\title{
Detergency of Soil Particles \\ Part 3 : Comparison of Reflectance and X-ray Fluorescence Method for Detergency Evaluation
}

\author{
Miyuki Akase $^{1 *}$, Teruo Tsunoda ${ }^{2}$ and Yuji YoneYama ${ }^{3}$ \\ ${ }^{1}$ Graduate School of Bunka Women's University \\ (Yoyogi, Shibuya-ku, Tokyo, JAPAN) \\ ${ }^{2}$ Bunka Women's University \\ (Yoyogi, Shibuya-ku, Tokyo, JAPAN) \\ ${ }^{3}$ Lion Corporation \\ (Hirai, Edogawa-ku, Tokyo, JAPAN)
}

Edited by K. Tajima, Kanagawa Univ., and accepted December 12, 2002 (received for review July 12, 2002)

\begin{abstract}
The detergency of clay particles on cotton cloth was evaluated based on the Kubelka-Munk equation for reflectance and X-ray fluorescence from $\mathrm{Al}, \mathrm{Si}$ and $\mathrm{Fe}$ in the particles prior to and after washing. In X-ray fluorescence the same detergency was observed for Al, $\mathrm{Si}$ and Fe. From this fact it may be said that particles were removed from cotton cloth. The order of detergency of clay particles for washing solutions was LAS/STPP $>$ STPP $>$ LAS $>$ pure water. The detergency based on the Kubelka-Munk equation for reflectance closely related to that from X-ray reflectance.
\end{abstract}

Key words: detergency, X-ray fluorescence, reflectance, evaluation, clay particle

\section{1 緒言}

衣類に付着する污れは，身体から分泌される皮脂な どの有機質污れと，泥などの無機質污れに大別される。 こうした污れを取り除く洗浄は, 界面活性剤の浸透, 膨潤, 乳化, 分散, 可溶化などの界面化学力の総和と, これに機械力が加わって成り立っており，そのメカニ ズムは非常に複雑な現象である。洗浄メカニズムに関 する研究は，これまでにも多く行われてきており，こ の中で粒子污れの洗浄メカニズムは, 疎水性コロイド として単純化して扱えることから，分散と安定性に関 する点から論じられている $(1-2)$ 。そして, 実際の洗 浄系にへテロ凝集理論を応用して解析することが試み られてきた (3-4)。

著者らは, 先にコロイド分散系にこの理論を応用し て洗浄結果を解析するために適した粒子污染布の作製 ならびに洗浄方法について検討し, 泥またはカーボン ブラックを污染する試験布の作製条件および機械作用
の抑制から，洗浄液の界面化学的作用の見やすい条件 を報告した（5）。次いで前報告では, 繊維および粒子 間の反発作用打よび引力作用の因子となるゼータ電位 打よび Hamaker 定数を測定して, 洗浄力との関係を検 討した。その結果, 洗浄液中に打ける粒子一繊維間の Hamaker 定数が小さくなる, 即ち, 粒子一繊維間の引 力作用が小さくなると洗浄率が増加した。また, 粒子 のゼータ電位は大きい程, 反発作用が多くなり, 洗浄 率は高くなった。これらの值を用いてへテロ凝集理論 によりポテンシャルエネルギーを算出し, 洗浄力の相 関を把握した（6）。しかしながら，粒子污れの洗浄性 を洗浄前後の污染布の表面反射率から算出しているこ とが，果たして粒子污れの脱離を正確に表しているの かを検証する必要があると思われる。そこで, 本研究 では洗浄前後の粒子污れの量についてけい光 X 線分析 法（XRF 法）を用いて定量し，反射率による洗浄率の 妥当性を検討した。

\footnotetext{
*Correspondence to: Miyuki AKASE, Graduate School of Bunka Women's University, 3-22-1, Yoyogi, Shibuya-ku 151-8523, Tokyo, JAPAN

E-mail: m-manabe@luck.ocn.ne.jp
} 


\section{2 実験}

\section{$2 \cdot 1$ 試料}

粒子污れとして三方ヶ原の粘土（赤黄色土）を用い， 試験布には油化学協会污染布用綿白布（晒カナキン 2023 番）を使用した。洗浄成分の界面活性剂として, 直鎖アルキルベンゼンスルホン酸ナトリウム（LAS，和 光純薬工業）打よびトリポリリン酸ナトリウム （STPP，米山薬品工業）を用いた。洗浄液は $5 \times 10^{-3}$ $\mathrm{mol} / \mathrm{L}$ の LAS 溶液, $1 \times 10^{-1} \mathrm{~mol} / \mathrm{L}$ の STPP 溶液, $\mathrm{LAS} / \mathrm{STPP}=5 \times 10^{-3} / 1 \times 10^{-1} \mathrm{~mol} / \mathrm{L}$ の溶液を用い た。

\section{$2 \cdot 2$ 污染布の作製}

乳鉢に粘土 $40 \mathrm{~g}$ を入れ, 乳棒で細かく擦りながら蒸 留水 $100 \mathrm{~mL}$ を少量ずつ添加してよく分散する。大型 シャーレに移し, 蒸留水 $300 \mathrm{~mL}$ を加えてマグネチック スターラーで筧找する。この粘土分散液に試験綿布 $(11 \times 11 \mathrm{~cm})$ を浸漬して污染した後，引き上げて自然 乾燥する。乾燥した後, 污染布をスポンジシートに置 き, 棒に巻いたスポンジシートで表裏 20 回づつラビン グして，余分な泥污れを除去する。污染布は $5 \times 5 \mathrm{~cm}$ に裁断し, 洗浄試験に用いた。試験布として, 表面反 射率が $55 \pm 5 \%$

\section{$2 \cdot 3$ 洗浄試験}

洗浄試験機にはターゴトメータ（上島製作所製）を 用いた。洗浄条件は, 洗剂液量 $900 \mathrm{~mL}$, 回転数 60 , $120,180 \mathrm{rpm}$, 洗浄温度を $30,40,50^{\circ} \mathrm{C}$, 洗浄時間 10 分 とし, すすぎは蒸留水 $900 \mathrm{~mL}$ ですすぎ時間 3 分を 2 回 行う。洗浄試験に用いた污染布は 5 枚一組とした。

洗浄率は下記に示す反射率法打よび XRF 法により求 めた。

\section{$2 \cdot 4$ 反射率法を用いた洗浄力算出}

試験布の反射率は, 携帯色差計（日本電色工業， NF902）を用い, 洗浄前後の布の表面反射率を測定し
た。洗浄力を反射率変化の百分率で求めた式（1）を 用いて, 洗浄率 $D_{R}$ を求めた。

$$
D_{R}=\frac{R_{w}-R_{s}}{R_{o}-R_{s}} \times 100(\%)
$$

ここで, $R_{o}$ は原白布, $R_{s}$ は污染布, $R_{w}$ は洗浄後の污染 布の表面反射率である。また, 反射率 $R$ と吸光度係数 $K$ 拈よび散乱係数 $S$ の関係式である Kubelka-Munk 式 を（2）より，K/S 值を算出し，洗浄前後の $K / S$ 值の変 化量から式（3）により洗浄力 $D_{k}$ を求めた。

$$
\begin{aligned}
& K / S=\frac{(1-R / 100)^{2}}{2 R / 100} \\
& D_{K}=\frac{(K / S)_{s}-(K / S)_{w}}{(K / S)_{s}-(K / S)_{o}} \times 100(\%)
\end{aligned}
$$

ここで, $K / S$ 值の添え字 $s, w, o$ はそれ年れ污染布, 洗浄 布, 白布を示す。

\section{5 けい光 $X$ 線強度を用いた洗浄力算出}

けい光 X線測定には, けい光 X線分析装置（理学電 機工業, System3270 型) を用いた。検出した元素は粘

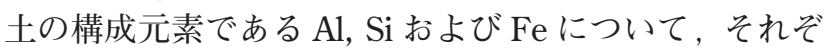
れ回折角度はそれぞれ 144.8 度，109.1 度，57.5 度にお けるけい光 X 線強度（CPS）を測定した。洗浄前後に 打ける CPS 值から，下式により洗浄率 $D_{X}$ を算出した。

$$
D_{X}=\frac{(C P S)_{s}-(C P S)_{w}}{(C P S)_{s}} \times 100(\%)
$$

ここで， $(C P S)_{s}$ は洗浄前の污染布からの XRF 強度， $(C P S)_{w}$ は洗浄後の污染布からの XRF 強度とした。

\section{3 結果と考察}

洗浄前後に打ける污染布の XRF 強度值とそれから算 出した洗浄率 $D_{X}$ を Table 1 に示す。洗浄液は蒸留水,

Table 1 Fluorescent X-rays Strength on the Test Cloth and Detergency $D_{X}$ under the Washing Condition of $120 \mathrm{rpm}$ and $30^{\circ} \mathrm{C}$.

\begin{tabular}{|c|c|c|c|c|c|c|c|c|c|}
\hline \multirow{2}{*}{ Solution } & \multicolumn{3}{|c|}{$\mathrm{Al}$} & \multicolumn{3}{c|}{$\mathrm{Si}$} & \multicolumn{3}{c|}{$\mathrm{Fe}$} \\
\cline { 2 - 11 } & $C P S_{s}$ & $C P S_{w}$ & $D_{X}(\%)$ & $C P S_{s}$ & $C P S_{w}$ & $D_{X}(\%)$ & $C P S_{s}$ & $C P S_{w}$ & $D_{X}(\%)$ \\
\hline Water & 22.09 & 4.28 & 83.8 & 23.60 & 4.63 & 84.0 & 1.78 & 0.41 & 78.8 \\
\hline LAS & 22.09 & 2.77 & 89.5 & 23.60 & 2.56 & 91.6 & 1.78 & 0.30 & 84.4 \\
\hline STPP & 22.09 & 1.88 & 92.5 & 23.60 & 2.27 & 91.8 & 1.78 & 0.17 & 90.8 \\
\hline LAS+STPP & 22.09 & 1.93 & 92.5 & 23.60 & 2.64 & 90.7 & 1.78 & 0.20 & 89.8 \\
\hline
\end{tabular}

(Kcps) 
LAS $\left(5 \times 10^{-3} \mathrm{~mol} / \mathrm{L}\right)$ 溶液, STPP $\left(1 \times 10^{-1} \mathrm{~mol} / \mathrm{L}\right)$ 溶液打よび LAS $\left(5 \times 10^{-3} \mathrm{~mol} / \mathrm{L}\right)$ と STPP $\left(1 \times 10^{-1}\right.$ $\mathrm{mol} / \mathrm{L})$ を混合した溶液を用い, 洗浄条件はターゴト メータの回転数を通常の家庭洗濯機の機械力に相当す る $120 \mathrm{rpm}$ とし, 洗浄温度 $30^{\circ} \mathrm{C}$ の条件下で洗浄実験を 行った結果である。 $\mathrm{Al}, \mathrm{Si}$ 扎よび $\mathrm{Fe}$ の各元素を検出し て求めた洗浄率はいずれも同じような值であり，特定 の元素が脱離していない, 即ち, 粘土粒子そのものと して脱離していると考えられる。このことから，これ 以降の XRF 法による検討では $\mathrm{Al}$ 元素だけを検出し, 洗 浄力 $D_{X}$ を算出することにした。

Table 1 に示した洗浄布について反射率を測定し, 反 射率法による 2 種の洗浄率を算出し, XRF 法から求め た洗浄率を比較した結果を Fig. 1 に示す。洗浄力は洗 浄液によって異なり，水 $<$ LAS $<$ STPP $<$ LAS $/$ STPP の順に洗浄は高くなっている。この順序は, 洗浄力の 算出方法のいずれもおいても同じであった。次に，洗 浄力の算出方法 $D_{R}, D_{K}$ 扎よび $D_{X}$ の間で比較すると, 水, LAS 溶液打よび STPP 溶液では $D_{R}$ が最も低い值で あり, 次いで, $D_{K}, D_{X}$ の順になっている。しかし， LAS/STPP の混合溶液の洗浄力では $D_{X}$ の值が低い值に なっている。これは，けい光 X線は布上に存在する粘 土粒子の存在量を全量検知しているのに対して, 表面 反射率は表面の変化だけを捕らえているため, LAS 溶 液扎よび STPP 溶液のような低めの洗浄率では, 粒子

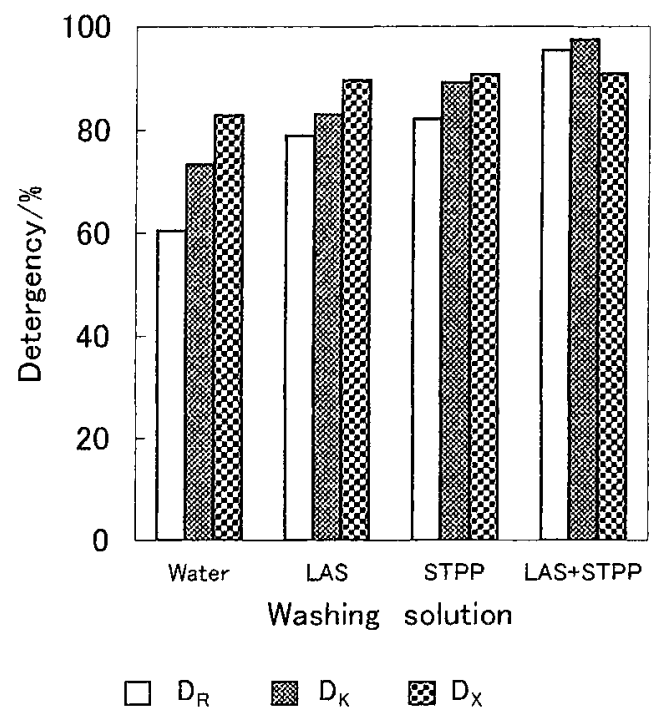

Fig. 1 Detergency $D_{R}$ and $D_{K}$ Caluculated by Use of Refrectance and Detergency $D_{X}$ Calculated by Use of Fluorescent Xrays Strength.

The washing condition is $120 \mathrm{rpm}$ and $30^{\circ} \mathrm{C}$.
污れの脱離を全量で捕らえられずに低く評価してしま うことが起因していると考えられる。反対に， LAS/STPP 溶液のように洗浄力が高いところでは， $D_{X}$ よりも $D_{R}, D_{K}$ の方が高い值となっている。これについ ては, 繊維内部に残存している粘土粒子が, 表面反射 率法では検出されずに, けい光 X線では検出されるた めに，洗浄性の值が逆転するためと考えられる。

次に, 機械作用と洗浄液の化学作用の総和という洗 浄の現象を考慮し, 洗浄温度 $(30,40,50$ 度）および回

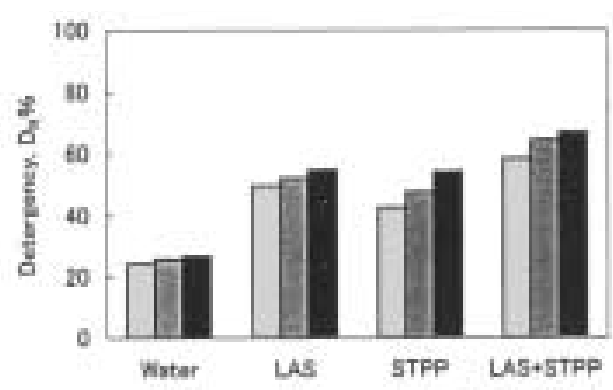

(a) $60 \mathrm{rpm}$

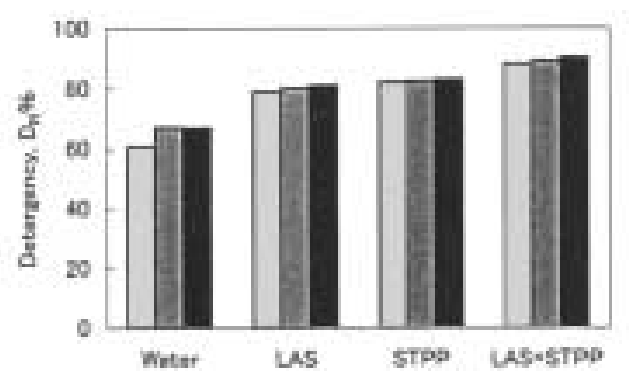

(b) $120 \mathrm{rpm}$

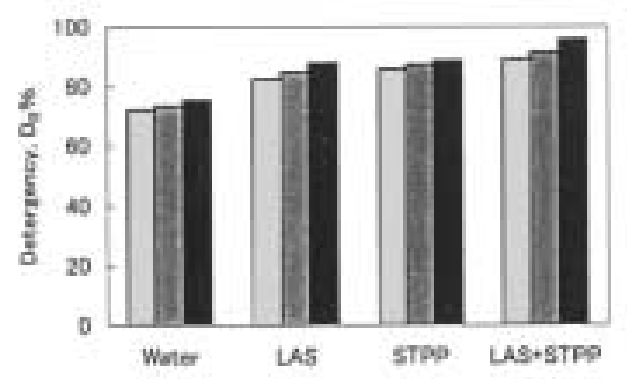

(c) $180 \mathrm{pm}$

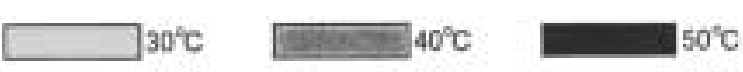

Fig. 2 Effect of the Washing Temperature and Rotation Number on Detergency $D_{R}$. 
転数（60,120,180 rpm）を変えて洗浄率を測定した。

Fig. 2 は反射率法の式（1）を用いて算出した洗浄率 $D_{R}$ の場合であり，Fig. 3 は，Kubelka-Munk 式を用い た洗浄率 $D_{K}$ の值である。

Fig. 2,3 から, 洗浄液の種類と洗浄率との関係は, Fig. 1 と同様に水 $<$ LAS $<$ STPP $<$ LAS と STPP の混 合水溶液の順に, 洗浄性は大きくなっている。また, 機械作用つまり回転数が増加するにつれ, 洗浄液間の 差異は小さくなっている。これは, 機械作用が小さい

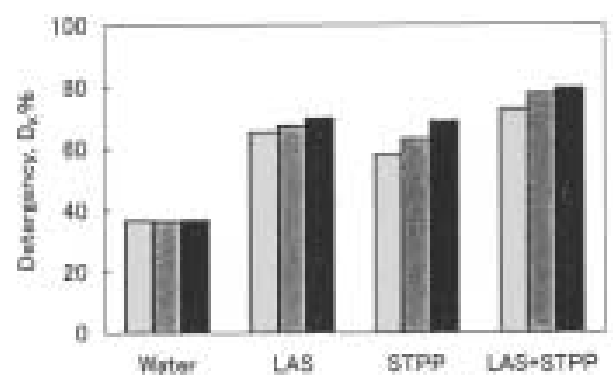

(a) $60 \mathrm{rpm}$

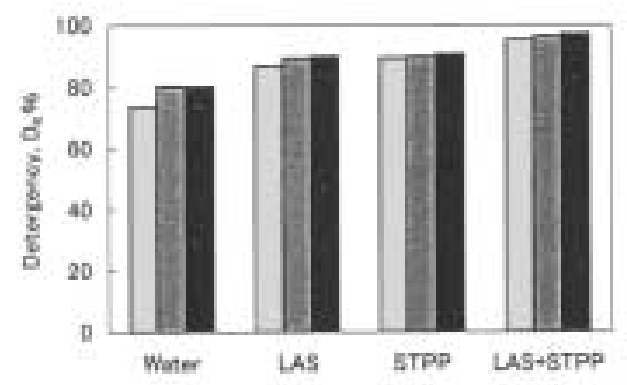

(b) $120 \mathrm{rgm}$

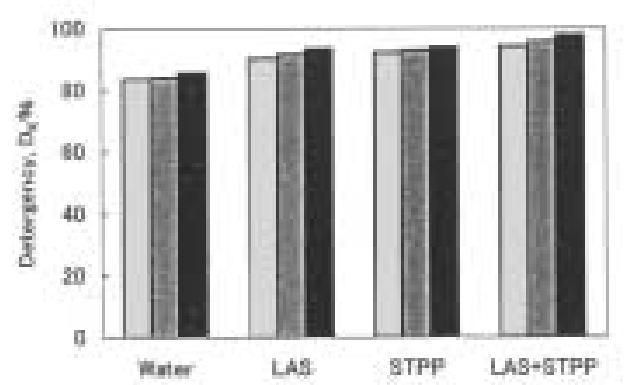

(c) $180 \mathrm{~mm}$

\section{$30^{\circ} \mathrm{C}$}
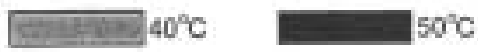

Fig. 3 Effect of the Washing Temperature and Rotation Number on Detergency $D_{K}$.
程化学作用の差がみられ，反対に機械作用が大きい程 化学作用の差が小さくなっており，機械作用の大きさ によって化学作用の効果が影響すると考えられる。洗 浄温度の影響は, 回転数が $60 \mathrm{rpm}$ の時にある程度の差 が見られ，高温度になる程洗浄率は高い值を示した。 一方, 回転数が $120 \mathrm{rpm}$ 以上では, 洗浄性に対する温 度の影響は回転数 $60 \mathrm{rpm}$ の場合と比較して小さくなっ た。これは回転数が大きい，即ち，機械作用が大きい 場合での粒子污れの除去性には，機械作用が大きな効

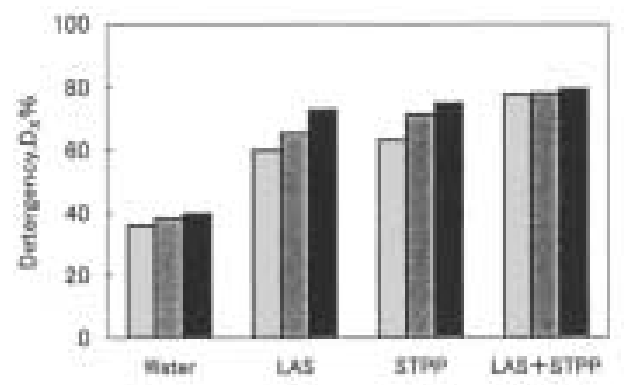

(a) $60 \mathrm{~mm}$

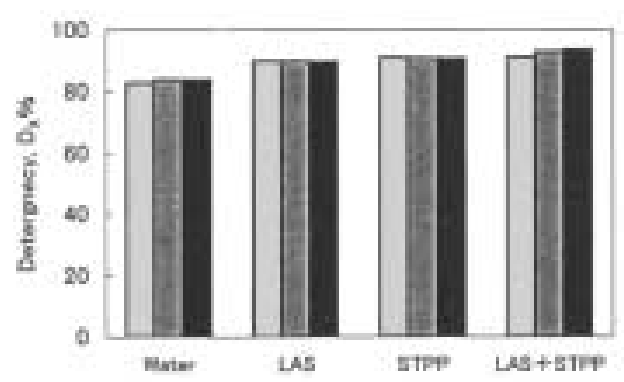

(b) $120 \mathrm{rmm}$

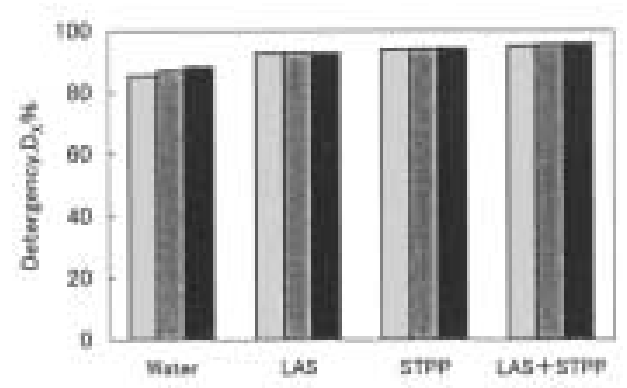

(e) $180 \mathrm{rpm}$

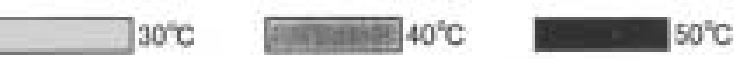

Fig. 4 Effect of the Washing Temperature and Rotation Number on Detergency $D_{X}$. 
果を持つと考えられる。

同じ污染布について洗浄前後の污染布上の粘土粒子 に含まれている $\mathrm{Al}$ 元素からの $\mathrm{X}$ 線強度から求めた洗浄 率 $D_{X}$ と, 洗浄条件との関係を Fig. 4 に示す。この結果 は, 反射率法で求めた洗浄性と比較し, 洗浄液の種類,

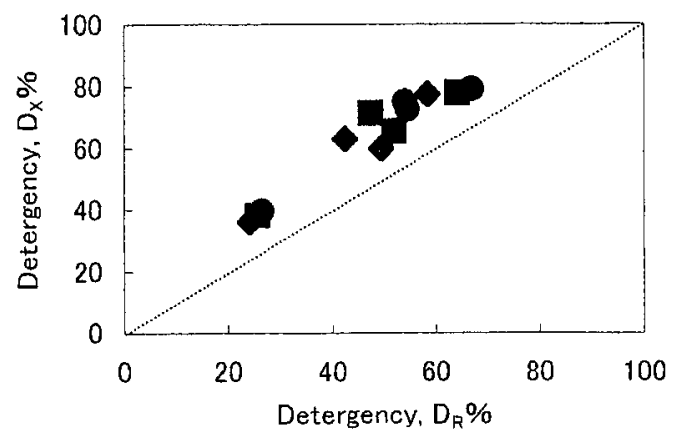

(a) $60 \mathrm{rpm}$

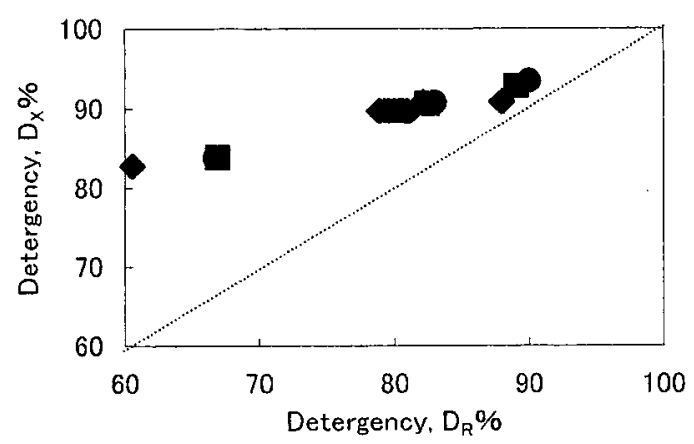

(b) $120 \mathrm{rpm}$

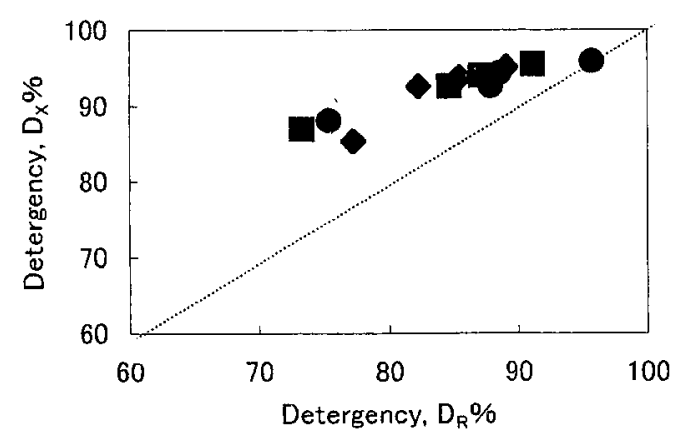

(c) $180 \mathrm{rpm}$

\section{$\rightarrow 30^{\circ} \mathrm{C} \quad-40^{\circ} \mathrm{C} \quad-50^{\circ} \mathrm{C}$}

Fig. 5 Relation between $D_{R}$ and $D_{X}$.
温度変化，回転数の変化をみるとほぼ同様の傾向を示 しており，特に Fig. 3 に示した反射率法の洗浄率 $D_{K}$ と 類似した結果である。

Fig. 2 の反射率法から求めた洗浄率 $D_{R}$ と Fig. 4 の $\mathrm{XRF}$ 法から求めた洗浄率 $D_{X}$ との関係をプロットする

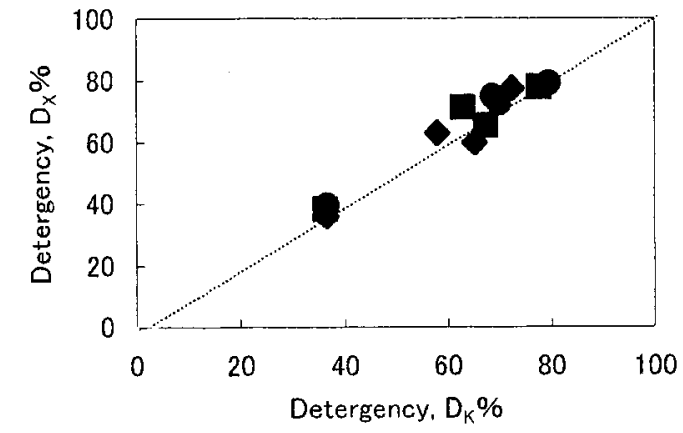

(a) $60 \mathrm{rpm}$

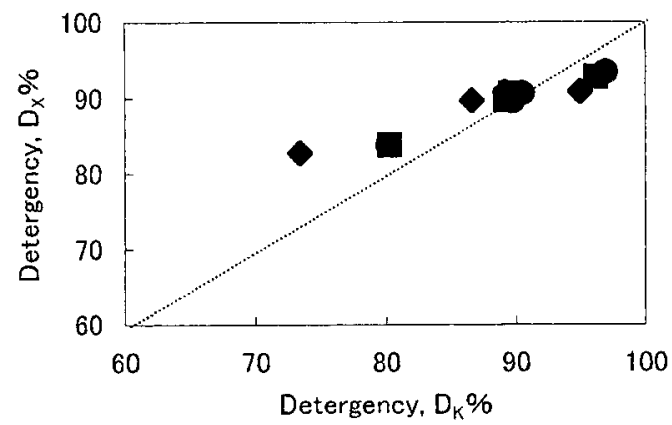

(b) $120 \mathrm{rpm}$

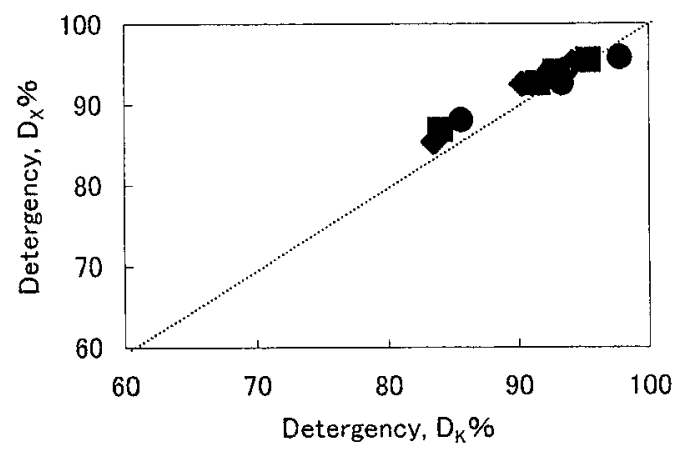

(c) $180 \mathrm{rpm}$

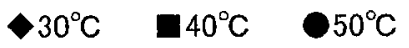

Fig. 6 Relation between $D_{K}$ and $D_{X}$. 
と, Fig. 5-a, b, c となる。同様に, Fig. 3 の反射率法か ら求めた洗浄率 $D_{K}$ と Fig. 4 の XRF 法から求めた $D_{X}$ の 洗浄性の関係をプロットしたものを Fig. 6-a, b, c に示 す。これらの結果から, 反射率法と XRF 法で求めた洗 浄率の間には, 洗浄率 $D_{R}$ と $D_{X}$ の間では相関性はあま り良くなく, Kubelka-Munk 式による洗浄率 $D_{K}$ と $D_{X}$ の間では良い相関性が見られた。これは，KubelkaMunkの式で算出した $K / S$ 值は光の吸収と散乱に関係す る物質の量と相関性があることから, Kubelka-Munkの 式を適用して求めた洗浄率 $D_{K}$ が, 反射率そのものより も污机量をより定量的に反映しているためと考えられ る。

前報 $(5,6)$ では，カーボンおよび粘土粒子の綿布か らの洗浄性抢よび, 繊維と粒子污れ間に働く引力に関 する Hamaker 定数と反発力に関するゼータ電位との対 応性について検討を行なっているが，このような考察 に打ける洗浄性の評価值には，定量性が必要である。 本報告ではけい光 X 線分析法により污れ量を測定し， 算出した洗浄率が，Kubelka-Munk 式から求めた洗浄率 との関性が良いという結果から，Kubelka-Munk 式で求
めた洗浄率は粒子污れの洗浄性を定量的評価するのは 妥当であることが分かった。

\section{References}

1. H. LANGE, Soluvent Properties of Surfactant Solutions (K. SHINODA, ed.), Mercel Dekker Inc., New York, pp. 117-187 (1967)

2. K. DURHAM, Proc. 2nd. Int. Cong. Surface Activity, IV, 60 (1957).

3. T. IMAMURA and H. TOKIWA, Relations between Desposition of Ferric Oxide onto Various Fabrics and Their Potential Energies in Aqueous Solutions of Sodium Tripolyphosphate and Sodium Chloride, J. Chem. Soc. Japan, 2177-2183 (1972).

4. Y. YONEYAMA, The Behavior of Zeolite in a Detergent Solution, Tenside Detergents, Vol. 19, 197-204 (1982).

5. M. AKASE, A. DOBASHI, T. TSUNODA, Preparation of Artificially Particle Soiled Clothes and Washing Conditions for Evaluation of Detergency, J. Jpn Res. Assn. Text. End-uses, Vol. 42, 595-600 (2001).

6. M. AKASE, A. DOBASHI, T. TSUNODA, Y. YONEYAMA, $J$. Jpn Res. Assn. Text. End-uses (Contributing) (2000). 